\section{Tethered insect flight: A computer program to analyze behavioral events}

\section{T. R. ASHLEY, J. L. SHARP, and D. L. CHAMBERS Insect Attractants}

Behavior and Basic Biology Research Laboratory Agricultural Research Service, USDA, Gainesville, Florida 32604

In entomological research, a flight mill is a piece of equipment used to analyze the flying ability of insects. The design and construction of an insect flight mill and the data-acquisition system that interfaces with the computer program presented herein are described by Chambers, Sharp, and Ashley (1976).

The purpose of this paper is to describe and illustrate the use of a computer program for analyzing behavioral data, in this instance, gathered from an insect flight-mill system consisting of 18 individual mills and an 18-channel event recorder that stores behavioral events on a seven-track computer tape. This computer program, written in FORTRAN IV, was planned so that individuals with little or no experience in computer techniques would be able to utilize it as part of their dataanalysis system. The program can be altered to interface with event recorders of different designs or with recorders of other behavioral events.

The terms experiment, treatment, replicate, record, recording, and flight are used to explain the versatility of the program and the punching of computer cards. An experiment is composed of one or more separate recordings. The major difference between experiments is a significant change in the datagathering conditions that necessitate altering the parameters set by the data cards. Each experiment is divided into treatments and replicates. A replicate consists of a single mill, and a treatment is composed of a group of mills having insects representing a common test parameter fastened to the mills. An individual recording starts when the event recorder commences to record and ends when either the stop button or the stop and file gap buttons are pressed. The event recorder automatically places a space on the computer tape at the end of each $1 \mathrm{~min}$ of recording. A record consists of the data between these spaces. Each recording is analyzed separately, and the number and length of the individual recordings placed onto a single tape are limited only by the length of the tape and the flight ability of the insects. A flight is defined as a period of activity not interrupted by a rest period longer than $2.5 \mathrm{sec}$. However, this definition can be varied.

Figure 1 (A) Output produced at the beginning of each recording; (B) General treatment analysis.
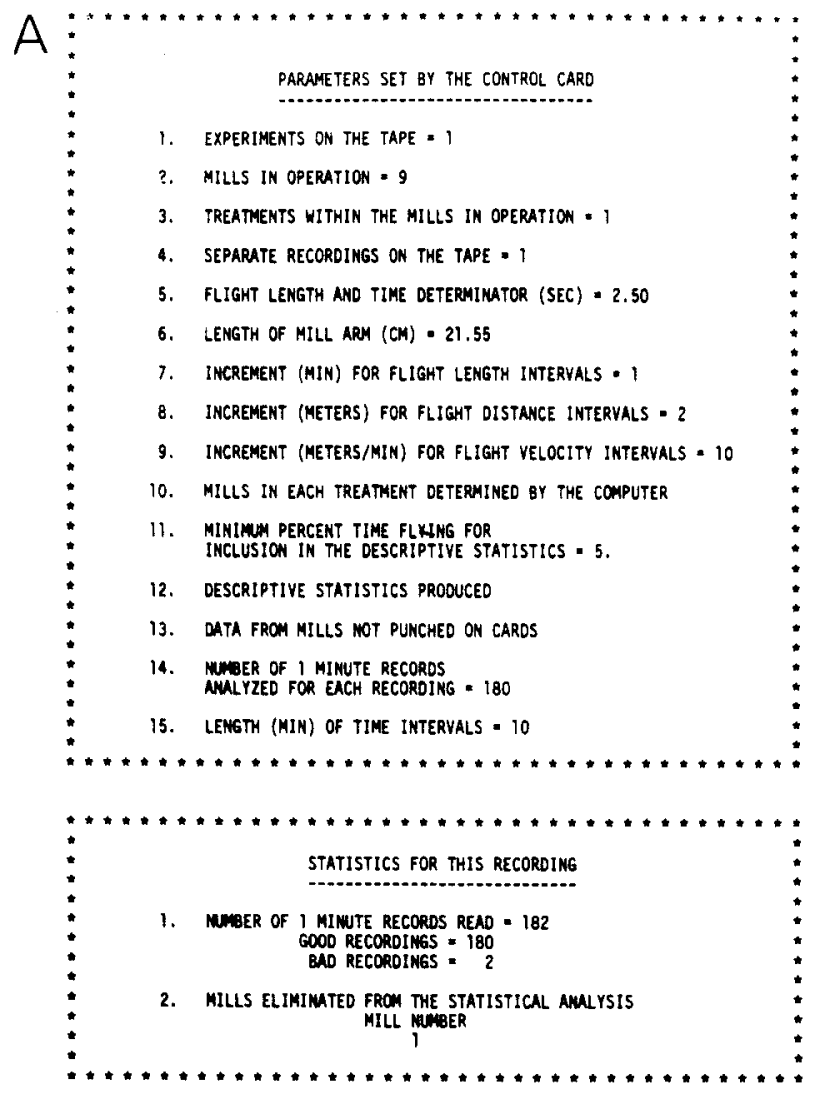

FLIGHT MILL STUDIES

PRIIMCIPA IIUTESTIGATOR(S) - T. R. ASHLEY, J. L. SHARP, MHO D. L. CHWWAERS PRIATION - IMSECT ATTRCTANTS, BEHAVIOR, MNO BASIC BIOLOGY RESEARCH LABORATORY
GAIMESVILLE, FLORIDA 32604

MUE OF INSECT - MUSTREPTU SUSPENSA (LOEW), CARIBBEAN FRUIT FLY EUERGEICE OATE - NUG 6, 1975

TEST DATE - AU6 16, 1975

TEST TIMES - BEGIWIMG 0900 ENDING 1200

EXPERIMEIT MUEER - 190

TAPE MUBER - FFO03
TEPERATURE - 27 DEG CEN

RELATIVE MMIOITY -70

LIEWT INTENSIT - 400 FT-C
BAPOITTRIC PRESSURE -29.62

TREATEEN - VIRGIM FGMLES, 10 DAYS QLD, MOT IRRNDIATED

RECORDING w. I OF I RECORDING(S)

TREATIERT 10 .

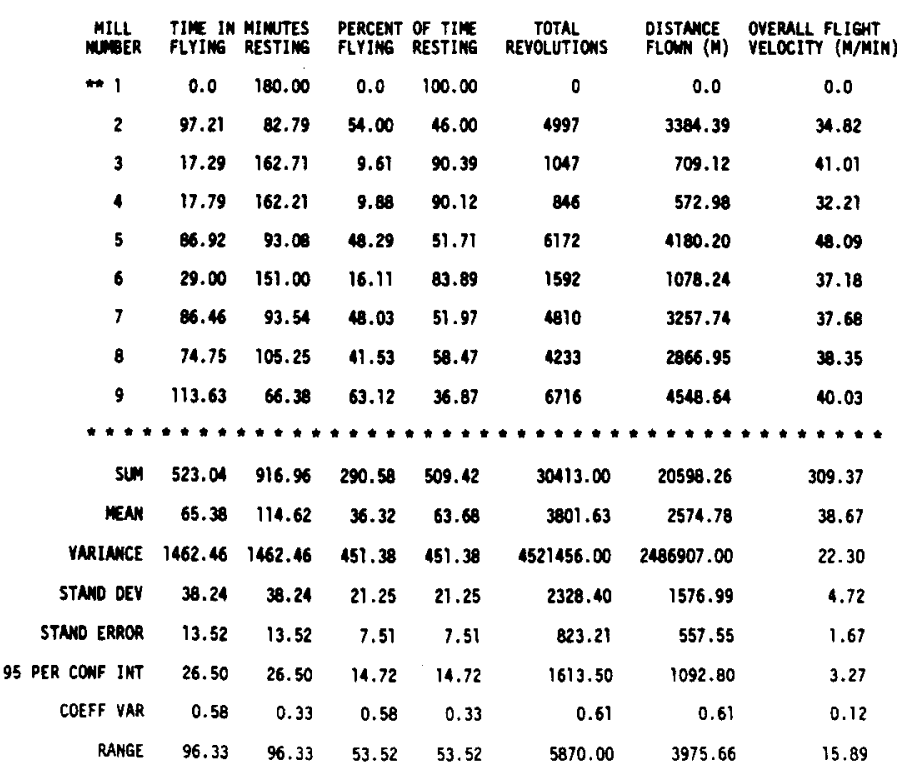




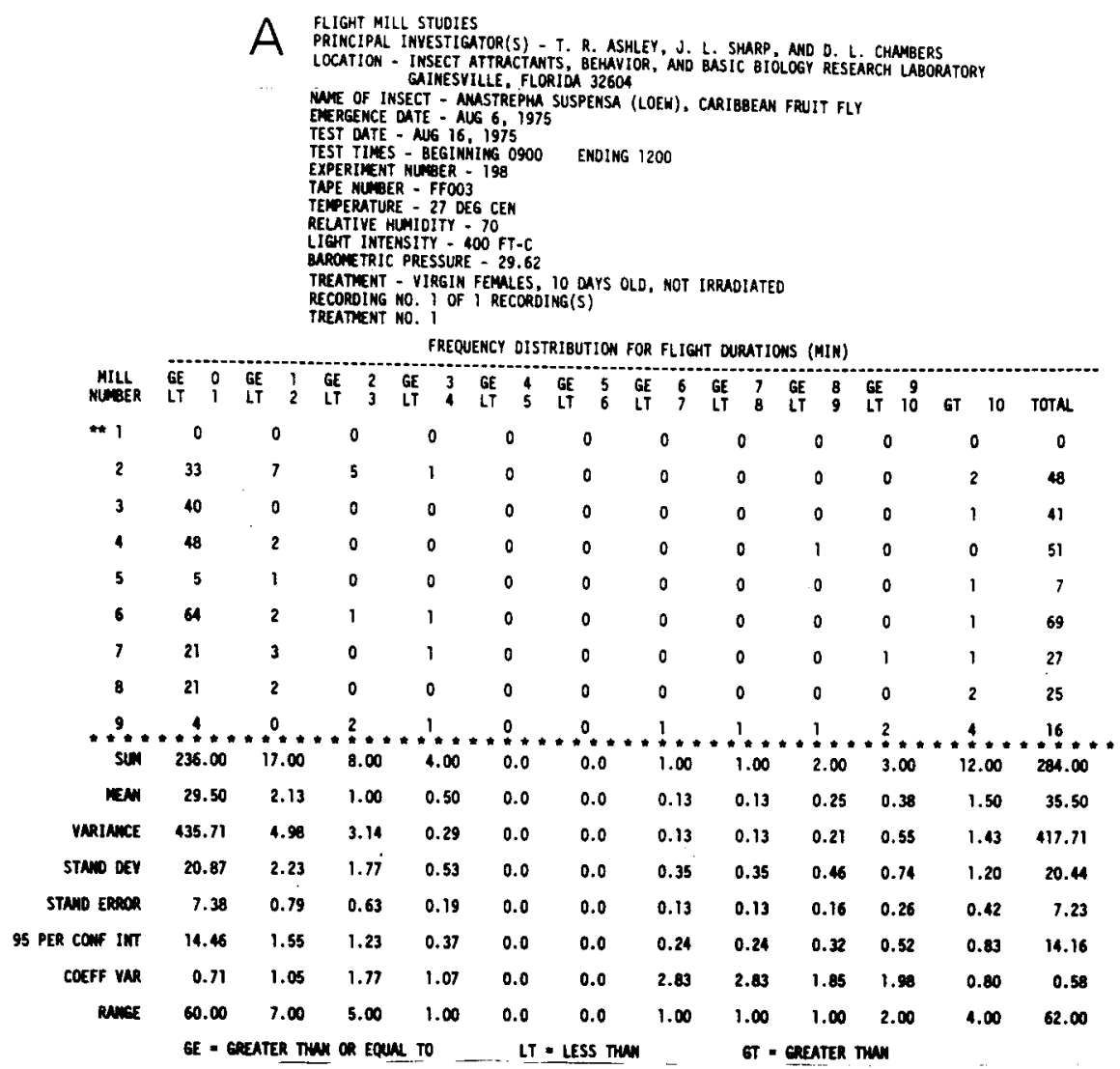

Output. The page of output produced at the start of each new recording consists of two sections (Figure 1A). The first defines and lists each of the parameters set by the data cards and should be examined carefully if the program was terminated by the computer or if the output was not of the desired format because an error on these cards may be responsible. The second section indicates the number of good and bad 1-min records read from the recording and lists the mills eliminated from the descriptive statistics because of insufficient activity.

The first 2 pages of the 20 pages of output produced for each treatment present a general analysis of the entire recording. The first page (Figure 1B) lists for each mill the time (minutes) flying and resting, percent time flying and resting, total revolutions, distance flown (meters), and overall flight velocity (meters/ minute). The overall flight velocity is calculated by dividing the total flying time (minutes) into the total distance flown (meters) during the recording. The second page (not illustrated, but having the same general format) presents an analysis of the individual flight having the greatest overall velocity (meters/ minute). This velocity is calculated by dividing the duration of the flight into the distance flown. In addition to giving the velocity for this flight, the computer calculates the flight's duration, number, time of occurrence, distance flown (meters), and number of revolutions. If the value " 3 " is given as the "flight number," the third flight of all the separate flights recorded for that insect had the greatest overall velocity. The "time of occurrence" is the amount of time from the start of the recording to the start of the flight.

Figure 2. (A) Frequency distribution for flight durations (minutes); (B) Time interval analysis for distance flown (meters).

FLIGHT MILL STUDIES

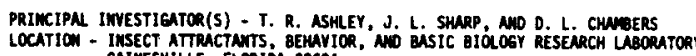
GIIMESVILLE, FLORIOA 32604

MOF OF IUSECT - MUSTREPH SUSPENSA (LOEW), CARIBAEN FRUIT FLY

DERGEMCE OATE - NU6, 6.1975

TEST TIRES - BEGIWIIMG 0900 ENDIMG 1200

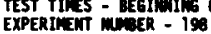

TWPE MTHER - FFOOJ

TEPERATURE - 27 DEG CEN

REGTIVE HUWIDIT -70

LIGH IMTESITY $400 \mathrm{FT}-\mathrm{C}$

TREATEEMT - VIRGIN FEMLES, 10 OAYS QD. MOT IRRADIATEO

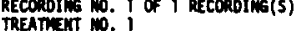

DISTAMCE FLOW FOR EACH MLLL DURING CONSECUTIVE 10 MIWUTE TINE INTERVALS

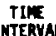

$\begin{array}{llllllllll}\text { INTERIAL } \\ \text { (HIN) } & 1 & 2 & 3 & 4 & 5 & 6 & 7 & 8 & 9\end{array}$

6T O LE $10 \quad$ O. 556 . 513. 344. 547.497 .492 .493 .545$.

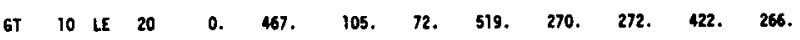

GT 20 LE 30 0. 414. 24. 50. 509. 167.425 .400 .429$.

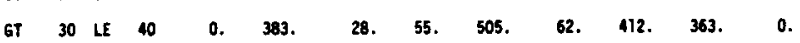

GT 40 LE 50 O. $339 . \quad$ 9. $22.469 . \quad 17 . \quad 394 . \quad 353 . \quad 0$.

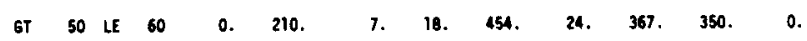

GT 60 LE 70 O. 173. 6. $0.435 . \quad 14.322 .307 .0$.

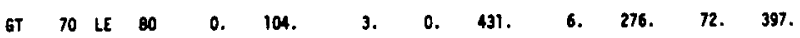

GT 80 LE 90 0. 123. 4. 3. 236. A. 125. 46. 404.

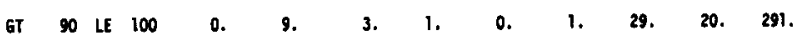

GT 100 LE 110 0. $0 . \quad 2 . \quad 0 . \quad 0 . \quad 1 . \quad 0 . \quad 15.338$.

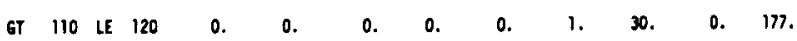

GT 120 LE 130 0. $0 . \quad$ 0. $0 . \quad$ 1. $0 . \quad 51 . \quad 14.154$.

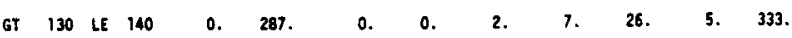

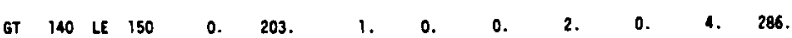

GT 150 LE 160 0. $0 . \quad 1 . \quad 0 . \quad 0 . \quad 1 . \quad 1 . \quad 0.354$.

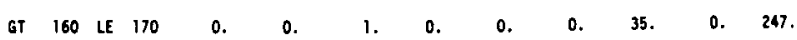

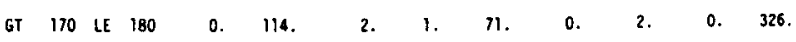


The next six pages of output consist of frequency and percentage distributions. The first of these pages, the frequency distribution for flight durations, is illustrated in Figure $2 \mathrm{~A}$. The next page of output which also analyzes flight durations has the same format except that the frequencies in each column shown in Figure $2 \mathrm{~A}$ are converted into percentages. The remaining tour pages present an analysis of flight distances and velocities and have the same general format as described for flight durations.

The remaining 12 pages of output present an analysis of the insects' flight activity with respect to time. This analysis is accomplished by dividing the duration of each recording into specified intervals. For each interval and mill in operation, the computer calculates the number of flights, distance flown (Figure 2B), amount of time flying, percent of each interval spent in flight, percent of the total time flying, and the overall flight velocity. The output for these calculations requires six pages. The other six pages give the descriptive statistics (same as those shown in the bottom portion of Figures $1 \mathrm{~B}$ and $2 \mathrm{~A}$, but arranged in a different format) for each of the above-cited variables.

A set of computer cards can be produced as part of the output on which the data for each mill and time interval have been punched. Recording these data on computer cards permits use of statistical programs available at most computer centers (Dixon, 1973; Nie, Bent, \& Hull, 1970; Service, 1972) and provides a permanent and easy-to-store record of the analyzed data.
As the data from each $1-\mathrm{min}$ record are read from the tape, the computer checks to see if a recording error has occurred. If an error is found, printed output is produced which indicates the location of the error on the tape. A recording error may result from a bad spot on the tape, a dirty tape, or a malfunction in the event recorder. Records containing errors are not included in the analysis.

Availability. A copy of this program punched on cards and an example of its output can be sent to interested individuals by contacting the senior author. No charge will be made for this service. The program will be sent as a "source" deck without job control language (JCL) cards.

\section{REFERENCES}

Chambers, D. L., Sharp, J. L., \& Ashley, T. R. Tethered insect flight: A system for automated data processing of behavioral events. Behavior Research Methods \& Instru. mentation, 1976, 8, 352-356.

Dixon, W. J. (Ed.). Biomedical computer programs. Berkeley, California: University of California Press, 1973

Nie, N., Bent, D. H., \& Hull, C. H. Statistical package for the social sciences. New York: McGraw-Hill, 1970.

SERVICE, J. A user's guide to the statistical analysis system. Raleigh, North Carolina: Student Supply Store, North Carolina State University, 1972. 